\title{
AS CIDADES-FORMADORAS DA INTELECTUAL, PROFESSORA E PESQUISADORA: RESENHA CRÍTICA DE UM LIVRO EM PRIMEIRA PESSOA
}

\author{
THE TRAINING CITIES OF AN INTELLECTUAL, \\ PROFESSOR AND RESEARCHER: CRITICAL \\ REVIEW OF A BOOK IN FIRST PERSON
}

\section{LAS CIUDADES DE FORMACIÓN DEL INTELECTUAL, DOCENTE E INVESTIGADORA: RESEÑA CRÍTICA DE UN LIBRO EN PRIMERA PERSONA}

\section{Marília Veríssimo Veronese ${ }^{1}$}

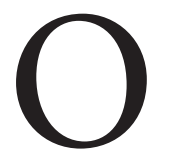

livro autobiográfico de Barbara Freitag-Rouanet, Peregrinação e aprendizado: Minhas cidades-formadoras, parte do debate acerca dos territórios-cidade que habitamos em momentos significativos de nossas vidas e que se tornam espaços formadores para sujeitos e coletividades. Em vez de discutir diretamente temas como a relação entre desigualdade social, segregação territorial, meio ambiente e educação (MARICATO, 2003), a intelectual teuto-brasileira opta por um entrelaçamento de suas experiências pessoais com os efeitos produzidos pelas cidades nas quais viveu, chegando ao conceito de cidades-formadoras.

O prefácio do livro coube à filha da autora, Adriana Bassi, que comenta a trajetória da mãe, destacando a difícil conciliação da maternidade com uma carreira vigorosa e uma atuação cidadã em prol do bem comum. Embora não esteja explicitada a perspectiva do gênero como categoria analítica, estão presentes elementos críticos das relações de gênero nas temporalidades das experiências do casal Freitag-Rouanet com a criação dos filhos e as respectivas carreiras profissionais.

O primeiro capítulo menciona o livro lançado em 2005, Itinerários de Bárbara Freitag, o qual constituiu uma síntese da trajetória acadêmica da autora. Nele, foram abordados os temas de pesquisa que a interessaram ao longo da vida, por meio de princípios metodológicos contidos na Teoria da Ação Comunicativa de Jürgen Habermas. Até pouco tempo atrás, conta Freitag, tal livro satisfazia-lhe como uma biografia sua; mas, ao completar 75 anos, aposentar-se e ganhar mais tempo para leitura e reflexões, sentiu vontade de produzir uma autobiografia mais pessoal, empreendendo uma incursão metodológica que unisse as experiências pessoais à obra intelectual.

Começa, a partir do segundo capítulo, uma viagem no tempo, que toma como fio condutor da narrativa a própria vida da autora. Do nascimento, na Alemanha de 1941, em plena Segunda Guerra Mundial, à imigração para o Brasil, passaram-se 6 anos:

A minha primeira viagem de trem, nos braços de minha mãe, esclarece o profundo entrelaçamento entre os destinos individuais e os processos históricos coletivos, cujas dimensões e amplitude somente conseguimos avaliar posteriormente, em um esforço de reconstrução e compreensão durante a vida adulta (FREITAG-ROUANET, 2019, p. 19).

Resenha do Livro: Peregrinação e aprendizado: Minhas cidades-formadoras, de Bárbara Freitag-Rouanet. Porto Alegre: Bestiário-Class, 2019. 1.Universidade do Vale do Rio dos Sinos - Porto Alegre (RS), Brasil. E-mail: mariliav@unisinos.br. 
A metodologia é apresentada pela análise sociológica dos acontecimentos que marcaram sua vida e provocaram essa itinerância entre cidades, que a fez fluente em várias línguas e a formou como mulher, cidadã e intelectual. Tal processo não é romantizado, mas narrado com as dores inerentes, como a perda precoce de seu pai. A autora vivenciou ataques aéreos, abrigos precários, frio e fome. Teve, entretanto, sua mãe e sua avó materna como referências afetivas e esteios familiares, acompanhando suas andanças e aprendizagens pelo mundo. Há uma articulação entre os fatores cognitivos e afetivos da formação pela vivência, como a dimensão subjetiva da experiência (TITTONI, 1994).

O pai, que ela não conheceu, e a mãe forneceram inputs para a narrativa autobiográfica, pois a autora utilizou-se de suas cartas e seus documentos, legados pela mãe após sua morte, para reconstruir as memórias, numa narrativa plausível, articulada pelas próprias lembranças. Assim, metodologicamente, houve acesso a um rico material documental, que atiçou o conteúdo mnêmico que Freitag-Rouanet utilizou em seu relato.

Na sequência, começa a narração da experiência brasileira. Aos 6 anos, ela já tinha passado por várias cidades, e a imigração para o Brasil com mãe, padastro e irmãos foi bem-sucedida. O país virou território formador para a família, chegada em Minas Gerais, na localidade de Itajubá. O grupo familiar lá residiu por um tempo, até se mudar para Porto Alegre (RS). Na capital gaúcha, Barbara passaria parte importante de sua juventude, antes de a cidade se tornar a capital do Orçamento Participativo e de outros elementos formadores de cidadania.

O próximo capítulo dá conta da formação acadêmica na Alemanha: acompanhada da avó, Freitag retorna à terra natal para cursar a universidade e lá estuda com Theodor Adorno e Max Horkheimer:

\begin{abstract}
Nessa ocasião Horkheimer e Adorno discutiam os problemas contemporâneos da sociedade de massas e seus mecanismos de comunicação; a filosofia do esclarecimento (da Grécia antiga aos dias de hoje); davam cursos de Introdução à Sociologia e Teorias da Modernidade. No decorrer das aulas e das conversas com meus pares fiquei sabendo mais sobre a trajetória desses pensadores judeus de língua alemã, perseguidos durante o período nazista, refugiados primeiro em Genebra e depois em Paris, e finalmente nos EUA (FREITAG-ROUANET, 2019, p. 47).
\end{abstract}

Depois disso, a autora estudou na Universidade Livre de Berlim, já envolvida com pesquisas na América Latina, à qual sempre esteve ligada profissional e emocionalmente. Essas pesquisas de campo são descritas e configuram um capítulo à parte no interesse da obra; pesquisas transnacionais, realizadas em um tempo em que não havia computadores pessoais e Internet. Um exemplo é a pesquisa de campo com pequenos agricultores cooperativados em Quito, Equador, que focava no âmbito socioeconômico, mas colocou-a em contato com questões de contracepção, machismo e outros elementos da vida das mulheres pobres do mundo rural.

A continuidade do livro dá conta da volta de Barbara Freitag-Rouanet ao Brasil e de sua atuação na Universidade de Brasília (UnB). No início dos anos de 1970, em plena ditadura, teria problemas de ordem política, por ser ligada a Florestan Fernandes e ter trabalhado em sua tese de doutorado com Celso Furtado e Gilberto Freyre, todos desafetos do regime autoritário. Apesar dos sustos, desenvolve carreira como docente e pesquisadora naquela instituição, de 1972 a 2002. Nesse período, conhece Sergio Paulo Rouanet, economista e diplomata, que viria a ser seu companheiro de vida e de trabalho.

Na segunda metade do livro, a vida familiar de Barbara passa a entrelaçar-se com o prosseguimento de sua carreira acadêmica e seu contínuo aprimoramento teórico e metodológico. A família vai para Zurique, e Barbara retoma as atividades acadêmicas, levando cartas de recomendação de Florestan Fernandes e Fernando Henrique Cardoso. A autora lecionou em Zurique, Frankfurt e Freiburg e elaborou e realizou um projeto 
de pesquisa com base na epistemologia genética de Jean Piaget, "buscando comparar o desenvolvimento psicogenético de crianças europeias e brasileiras, estudadas por Lauro de Oliveira Lima no Rio de Janeiro e Esther Grossi no Rio Grande do Sul." (FREITAG-ROUANET, 2019, p. 91).

De volta ao Brasil, Freitag descreve passagem por Brasília, em que reassumiu as atividades docentes na UnB e formou turmas de pós-graduandos de diversas origens. Além disso, seguiu nas pesquisas piagetianas, trabalhando com crianças periféricas da cidade satélite de Ceilândia (DF). O Brasil, em fase de redemocratização, havia retirado os obstáculos à pesquisa de teor crítico, e a autora teve uma fase fértil de produção acadêmico-científica.

O capítulo oito, "No reino da Dinamarca", título que referencia a obra shakespeariana, relata a experiência da família em Copenhague, onde Freitag aprofundaria os estudos sobre aquisição da linguagem escrita, tomando como mote o processo de alfabetização de uma trabalhadora doméstica brasileira. A história de Maria, mulher pobre e analfabeta que foi iniciada nas letras pela intelectual, é um dos pontos altos do livro. Bárbara dava aulas por duas horas todas as manhãs e manteve um diário de campo sobre a experiência, que depois serviria de registro empírico para o livro Diário de uma alfabetizadora, editado pela Papirus em 1988: "Mantive um diário sobre essas aulas, em que procurei conciliar os meus conhecimentos do pensamento cognitivo, da moral e da fala piagetianos com a prática de alfabetização para adultos desenvolvida por Paulo Freire" (FREITAG-ROUANET, 2019, p. 109). Naquele período, entre 1987 e 1990, ainda escreveria Itinerários de Antígona: A questão da moralidade e ministraria cursos na Universidade de Berlim.

No final do livro, descreve-se a experiência checa da família itinerante, na Praga já redemocratizada. Nesse período, Freitag lecionaria na Universidade de Praga quatro semestres de aulas em inglês, alemão e português. O ensino em língua estrangeira é uma porta aberta para a internacionalização das universidades, tendo essa prática se intensificado no Brasil mais recentemente (MOROSINI; NASCIMENTO, 2017).

No capítulo final, as cidades-formadoras são tematizadas: os conceitos de "cidades essenciais" e "cidades estruturantes" são tomados da arquitetura e do urbanismo:

como uma espécie de andaime que permitisse relembrar e organizar as reminiscências de uma vida em movimento em tempos agitados da II Guerra Mundial, da condição de refugiados e imigrantes de um continente para o outro, de uma espécie de perambulação entre a Europa e a América Latina, mais especificamente entre Alemanha e Brasil (FREITAG-ROUANET, 2019, p. 134-135).

Tais conceitos, retrabalhados, inspiram o de "cidades-formadoras", as quais proporcionariam algo como uma matriz psíquica na memória cognitivo-afetiva, orientadora das experiências e dos aprendizados dos sujeitos pelo mundo. Na sociologia urbana, conclui a autora, "podemos falar da cidade como instituição formadora (ou não), do indivíduo autônomo e da coletividade civilizada" (FREITAG-ROUANET, 2019, p. 135).

É nessa última seção do livro que a elaboração teórica acerca do papel dos territórios-cidade que nos abrigam, em momentos significativos de nossas vidas, é levada a cabo. Eles funcionam como "instituições formadoras", fontes de aprendizagem, palcos de processos de subjetivação e formação em vários níveis. No Brasil, foram Itajubá, Porto Alegre e Brasília; na Europa: Frankfurt, Darmstadt e Berlim, além das outras muitas que a autora frequentou e que lhe deram uma perspectiva intercultural de mundo, uma cosmovisão calcada nos ideais da paz, da razão e da solidariedade como estruturantes éticos de ações no mundo e de constituição de valores morais orientadores para a vida. 


\section{Referências}

FREITAG-ROUANET, B. Peregrinação e aprendizado: Minhas cidades-formadoras. Porto Alegre: BestiárioClass, 2019.

MARICATO, E. Metrópole, legislação e desigualdade. Estudos Avançados, São Paulo, v. 17, n. 48, p. 151166, ago. 2003. https://doi.org/10.1590/S0103-40142003000200013

MOROSINI, M.; NASCIMENTO, L. Internacionalização da educação superior no Brasil: A produção recente em teses e dissertações. Educação em Revista, Belo Horizonte, v. 33, 2017. http://doi. org/10.1590/0102-4698155071

TITTONI, J. Subjetividade e trabalho. Porto Alegre: Ortiz, 1994.

\section{Sobre a Autora}

Marília Veríssimo Veronese é doutora em Psicologia Social pela PUCRS (2004). Pós-doutora em Sociologia pelo Centro de Estudos Sociais da Universidade de Coimbra (2020). Docente e pesquisadora do Programa de Pós-Graduação em Ciências Sociais (PPGCS) da Unisinos.

Recebido: 17 Mar 2020.

Aceito: 31 Mar 2020 